\title{
Erufosine, a novel alkylphosphocholine, in acute myeloid leukemia: single activity and combination with other antileukemic drugs
}

\author{
Michael Fiegl • Lars H. Lindner • Matthias Juergens • \\ Hansjoerg Eibl · Wolfgang Hiddemann · Jan Braess
}

Received: 12 July 2007 / Accepted: 17 September 2007/Published online: 6 October 2007

(C) Springer-Verlag 2007

\begin{abstract}
Purpose Alkylphosphocholines represent a new class of cytostatic drugs with a novel mode of action. Erufosine (ErPC3), the first compound of this class that can be administered intravenously, has recently been shown to be active against human tumor and leukemic cell lines.

Methods In order to evaluate the antileukemic potential of ErPC3 in acute myeloid leukemia (AML) the lethal concentration 50\% (LC 50) was determined using WST-1 assay. For analysis of cell death, staining for Annexin V and activated caspase 3 was performed. An interaction analysis was performed by calculation of combination index and construction of isobolograms.

Results The LC 50 was $7.4 \mu \mathrm{g} / \mathrm{ml}$ after $24 \mathrm{~h}$ and $3.2 \mu \mathrm{g} /$ $\mathrm{ml}$ after $72 \mathrm{~h}$ in HL 60 cells and 30.1 and $8.6 \mu \mathrm{g} / \mathrm{ml}$, respectively, in 19 fresh samples from patients with AML.
\end{abstract}

M. Fiegl · L. H. Lindner - M. Juergens · W. Hiddemann ·

J. Braess $(\bowtie)$

Laboratory for Leukemia Diagnostics,

Department of Internal Medicine III,

University Hospital Grosshadern,

Ludwig-Maximilians University,

Marchioninistr. 15, 81377 Munich, Germany

e-mail: Jan.Braess@med.uni-muenchen.de

L. H. Lindner

Institute of Molecular Immunology,

GSF-National Research Center for Environment

and Health, Munich, Germany

W. Hiddemann

Clinical Cooperative Group Acute Myeloid Leukemia,

GSF-National Research Center for Environment and Health,

Neuherberg, Germany

H. Eibl

Max Planck Institute for Biophysical Chemistry,

Göttingen, Germany
ErPC3 was found to be cytotoxic in HL60 cells with distinct activation of caspase 3. ErPC3 was not cross-resistant with cytarabine, idarubicine and etoposide as shown by the linear relation of respective LC 50s. The latter agents, however, exerted an additive cytotoxicity in combination with ErPC3 as revealed by isobologram analysis and combination index, although results are uneven for idarubicine.

Conclusion Based on these data ErPC3 appears as a novel antileukemic candidate drug, which needs to be explored further in the treatment of AML.

Keywords AML · Alkylphosphocholine - Cytarabine . Cytotoxicity $\cdot$ Interaction analysis

\section{Introduction}

The combination of cytarabine with an anthracycline has remained the therapeutic standard in the treatment of acute myeloid leukemia (AML) for over three decades. The improvements in remission rate and long-term survivors achieved during that time were due to an intensification of therapy and improvements of supportive therapy. Clearly there is a need for new promising antileukemic agents.

Alkylphosphocholines represent a new class of lipophilic drugs that interact with the cell membrane [16, 18, 27], the so called "membrane active lipids". They also modulate intracellular signal transduction pathways. Their exact mechanism of action still remains to be elucidated in detail. To date they have been shown to exert apoptosis in many cancer models $[9,16]$ and also leukemic cell lines [7, $14,15]$. Various interactions with intracellular signaling have been found, e.g., activation of c-myc [20] and inhibition of MAPK [23] and PI3K/Akt survival pathways [24]. As cytarabine in its active form as Ara-CDP choline is 
supposed to interact with cellular membranes as well [2, 13], it could resemble a very interesting combination partner for erufosine.

The class of alkylphosphocholines comprises various compounds, from which only one, hexadecylphosphocholine (miltefosine, HePC) has been introduced into clinical practice. HePC can be used topically for local control of skin metastases of breast cancer [17] and orally for eradication of visceral leishmaniasis [10]. The major disadvantage of this class of compounds is their poor gastrointestinal tolerability after oral application leading to insufficient plasma levels for systemic cancer treatment. An intravenous application of micelle-forming $\mathrm{HePC}$ and analogue alkylphosphocholines is impossible due to intravascular hemolysis. In addition, the recent experience with alkylphosphocholines as drugs in the treatment of cancer and leishmaniasis clearly demonstrated that the use of saturated alkyl chains results in a narrow therapeutic index. More favored and superior are alkylphosphocholines with one cis-double bond in the alkyl chain, for instance oleoylphosphocholine and erucylphosphocholine. These compounds have better efficacy and a much larger safety margin [1, 25].

One prototype of alkylphosphocholines with cis-double bond is erucylphosphohomocholine (erufosine, ErPC3), which has been shown to be applicable intravenously in animals with a high efficacy against tumor models in animals and various tumor or leukemic cell lines in vitro [7, 9].

The present study investigated the antileukemic potential of erufosine in AML in vitro both in leukemic cells lines and fresh patient samples. In addition, the mode of action of erufosine in AML and possible synergisms with the most commonly used drugs cytarabine, idarubicine (as an example for anthracyclines) and etoposide (as topoisomerase II inhibitor) were investigated.

\section{Patients and methods}

Patients and cell culture

Samples from adult patients ( $\geq 18$ years) with first diagnosis of AML were included into this study. Diagnosis was based on cell morphology according to FAB criteria complemented by cytochemistry and immunophenotyping. A bone marrow infiltration of $>70 \%$ and collection of a sufficient number of bone marrow cells ( $>10^{8}$ cells) during the initial diagnostic bone marrow aspiration was required. The conduct of the study was performed in accordance with the Declaration of Helsinki and was approved by the local ethics committee. All patients were informed of the investigational nature of the study and gave their informed consent.
Leukemic blasts were collected by bone marrow aspiration and subsequently subjected to Ficoll hypaque centrifugation. Prior studies have shown that following Ficoll hypaque centrifugation purity $>90 \%$ of leukemic blasts can be obtained. Cells were diluted to a concentration of $1 \times 10^{7}$ cells/ml in Iscove's Modified Dulbecco's Medium (IMDM), which was supplemented with $20 \mathrm{mM}$ HEPES, $100 \mu \mathrm{g} / \mathrm{ml}$ streptomycin, $10 \mathrm{mM}$ L-glutamine and $10 \%$ FCS. Cultures were kept at $37^{\circ} \mathrm{C}, 5 \% \mathrm{CO}_{2}$ and $95 \%$ humidity. Before incubation viability was checked by trypan blue exclusion test and only samples with a viability exceeding $80 \%$ were accepted for subsequent experiments. Blasts from the HL 60 cell line were processed in analogy for some of the experiments.

\section{Drugs and media}

Erufosine was kindly provided by H. Eibl and L. Lindner. Cytarabine (AraC) was obtained from CellPharm (Hannover, Germany), idarubicine was from Pharmacia (Karlsruhe, Germany) and etoposide was from Hexal (Holzkirchen, Germany). Cell culture medium (IMDM), PBS, HEPES, streptomycin, L-glutamine and fetal calf serum were purchased from Gibco Life Technologies (Eggenstein, Germany). WST-1 reagent was available from Roche Diagnostics (Mannheim, Germany). An OPTImax ELISA reader by Molecular Devices (Munich, Germany) was used.

\section{Determination of LC 50}

The overall viability of cell samples was measured by the WST-1 assay. Briefly this assay is based on the cleavage of the tetrazolium salt WST-1 to a (colored) formazan dye by mitochondrial dehydrogenases of viable cells. The signal can be detected spectrophotometrically in an ELISA reader and directly correlates to the number of viable and metabolically active cells in the sample. The assay was performed in 96-well plates with $100 \mu \mathrm{l}$ of a $10^{6} \mathrm{AML}$ blasts/ml suspension.

Following drug exposure with increasing concentrations (ErPC3: $0.5-100 \mu \mathrm{g} / \mathrm{ml}$, AraC: $0.1-100 \mu \mathrm{g} / \mathrm{ml}$, idarubicine: $0.1-1 \mu \mathrm{g} / \mathrm{ml}$, etoposide: $0.1-50 \mu \mathrm{g} / \mathrm{ml}$ ) for exposure times of 24 up to $96 \mathrm{~h} 10 \mu \mathrm{l}$ of WST-1 reagent were added to the $100 \mu \mathrm{l}$ cell suspension for a further incubation of $4 \mathrm{~h}$. The ELISA reader was set at a wavelength of $450 \mathrm{~nm}$ with a reference wavelength of $690 \mathrm{~nm}$. The results following drug exposure were calculated as a percentage relative to untreated controls and plotted in semi-logarithmic doseeffect curves. Using these data points a curve was fitted (4-parameter fit: $y=\left\{(A-D) /\left[1+(x / C)^{B}\right]+D\right\} \quad$ [19], 
which was then used to interpolate the LC 50 (thehypothetical-concentration that would reduce the viability of the cell population to $50 \%$ as compared to the untreated control).

\section{Determination of concentration coefficient $N$}

The concept of the concentration coefficient $N$ is described in detail elsewhere [4]. In brief, it is based on the finding that the equation $C \times T=$ constant $(C=$ concentration of drug, $T=$ exposure time of the drug) is not sufficient to describe the pharmacodynamic relationship between both parameters for several cytotoxic agents (e.g., cytarabine) to achieve a certain cell kill. Therefore, the concentration is modified with an index $N$, resulting in the equation $C^{N} \times T=$ constant. When $N=1, C$ and $t T$ are equally important in achieving a certain effect, e.g., LC 50. When $N>1, \mathrm{C}$ is more important for a drug than $T$, i.e., that halving $C$ cannot be compensated by doubling $T$. $N<1$ is found for drugs that are dependent on long exposure times rather than on high concentrations. The detailed method to determine $N$ has been described by our group recently $[4,6]$. In brief, double logarithmic transformation of a time/concentration isoeffective analysis results in a linear relationship from which the parameter $N$ can be extracted as the negative gradient.

\section{FACS analysis for detection of apoptosis}

The cells from the HL 60 cell line were incubated at a concentration of $10^{6}$ cells $/ \mathrm{ml}$ for $78 \mathrm{~h}$ and then exposed to $50 \mu \mathrm{g} / \mathrm{ml}$ of ErPC3 for $4 \mathrm{~h}$. The cells were then washed with ice-cold PBS buffer. For Annexin V staining, a commercially available kit by Becton Dickinson was used. In brief, the cells were washed twice in ice-cold PBS buffer and diluted tenfold. The cells were then stained with Phycoerythrin (PE) conjugated antibodies against Annexin $\mathrm{V}$ and counterstained with 7-Amino-actinomycin D (7-AAD, a color dye enriched in dead cells). After incubation for $15 \mathrm{~min}$ in the dark at room temperature, cells were diluted with $300 \mu \mathrm{l}$ buffer and then measured without gating within $1 \mathrm{~h}$ with FACSCalibur with CellQuest software (Becton Dickinson, Heidelberg, Germany) on an Apple Macintosh computer.

In addition, the active caspase 3 kit from Becton Dickinson was used. In brief, after exposure to ErPC3 as mentioned above the cells were fixed and permeabilized with the Cytofix/Perm Puffer provided within the kit for $30 \mathrm{~min}$ on ice. The cells were then washed twice and diluted tenfold. Staining was performed with PE conjugated anti-caspase 3 antibodies at $4^{\circ} \mathrm{C}$ in the dark for
20 min. Afterwards, the cells were washed and measured as mentioned above. All experiments were performed in triplicate.

Interaction analysis

For interaction analysis fixed ratios of combinations as determined by the relationship of the respective LC 50s in $\mathrm{ng} / \mathrm{ml}$ determined in HL60 cells [erufosine : $\mathrm{AraC}=1: 0.2$ (molar relationship 1:0.42), erufosine:idarubicine $=$ 1:0.0025 (molar relationship 1:0.003) and erufosine:etoposide $=1: 0.2($ molar relationship 1:0.17) $]$ were used. The combination index (CI) was calculated according to the following formula [12]:

$\mathrm{CI}=\frac{\mathrm{C}_{\mathrm{c}} \mathrm{X}}{\mathrm{C}_{\mathrm{i}} \mathrm{X}}+\frac{\mathrm{C}_{\mathrm{c}} \mathrm{Y}}{\mathrm{C}_{\mathrm{i}} \mathrm{Y}}+\alpha \frac{\left(\mathrm{C}_{\mathrm{c}} \mathrm{X}\right)\left(\mathrm{C}_{\mathrm{c}} \mathrm{Y}\right)}{\left(\mathrm{C}_{\mathrm{i}} \mathrm{X}\right)\left(\mathrm{C}_{\mathrm{i}} \mathrm{Y}\right)}$

where $\mathrm{C}_{\mathrm{c}} \mathrm{X}$ is the $\mathrm{LC} 50$ of $\operatorname{drug} \mathrm{X}$ in combination with drug $\mathrm{Y}, \mathrm{C}_{\mathrm{i}} \mathrm{X}$ is the individual LC 50 of drug $\mathrm{X}, \mathrm{C}_{\mathrm{c}} \mathrm{Y}$ the $\mathrm{LC}$ 50 of drug $Y$ in combination with drug $X$ and $C_{i} Y$ is the individual LC 50 of drug $\mathrm{Y} ; \alpha=1$ or 0 depending on whether both drugs are assumed to be mutually nonexclusive or mutually exclusive in their action respectively. According to this method, synergy is assumed when the CI is less than 1, additivity when the CI equals 1 and antagonism by a CI greater than 1 .

For isobologram analysis, we used the method of Steel and Peckham [26], modified by Kano et al. [11]. For detailed description and theoretical background, please refer to these publications. In brief, the isobologram shows the relationship of the dose of drugs $\mathrm{X}$ and $\mathrm{Y}$ to achieve a certain effect, in this case LC 50. From the two individual LC 50s derived by dose-response curves and the calculation of Mode I and Mode II lines (see below), the so-called "envelope of additivity" can be drawn (see Fig. 1). The measured LC 50s of the combination of both drugs falling in this area are assumed to be additive to each other (example point A), combinations falling below are assumed to be supra-additive (example point B) while combination values above the envelope are assumed to be sub-additive (example point $\mathrm{C}$ ). The combination points above the square defined by both individual LC 50s are defined to be protective, i.e., antagonistic (example point D). Note that not absolute concentrations but relative values were used for the calculation.

\section{Mode I line}

When the dose of drug $\mathrm{X}$ is chosen there remains an increment in effect to be produced by drug Y. If two drugs were to act independently, the addition is performed by 


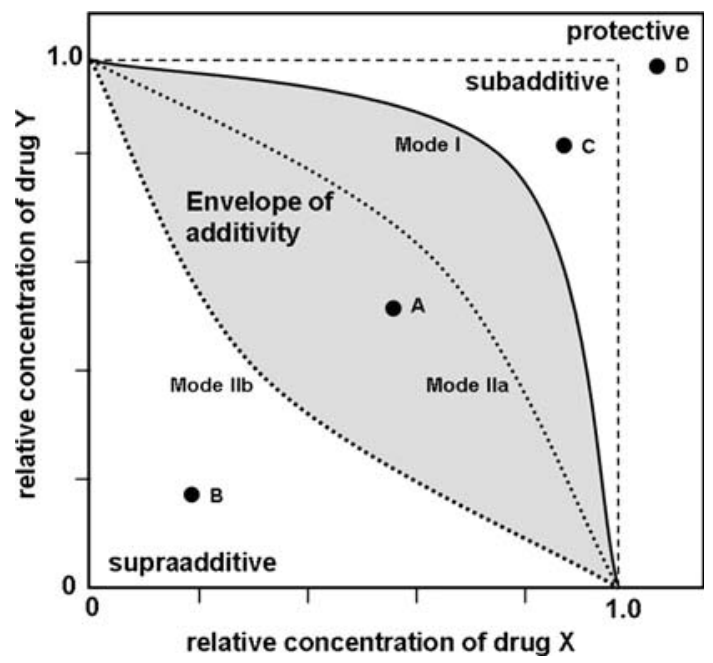

Fig. 1 Schema of isobologram analysis (for detailed information refer to text). The grey area enclosed by Mode I and Mode IIb line defines the envelope of additivity. Point $A$ represents an additive combination of drug $\mathrm{X}$ and drug Y. Combinations (point B) falling under this area are supraadditive, combinations above subadditive (point C). Combinations beyond the square defined by LC 50s of individual drug $\mathrm{X}$ and drug $\mathrm{Y}$ values are considered to be protective (or antagonistic, point $D$ )

taking the increment in doses, starting from 0 that give survivals, which add up to LC 50 .

\section{Mode IIa line}

When the dose of drug $\mathrm{X}$ is chosen, an isoeffect curve can also be calculated by taking the dose increment of drug $\mathrm{Y}$ that gives the required contribution to the total effect up to the limit, in this case LC 50.

\section{Mode IIb line}

Similar as mode IIa for drug Y.

\section{Results}

Patients' characteristics

Samples of 19 patients with AML were examined. Median age was 62.5 years (40-84 years) with 15 male and 4 female patients. Distribution of FAB subtypes was as follows: M0 three patients, M1 four patients, M2 seven patients, M4 four patients and M5 one patient. Unfavorable karyotypes were seen in eight patients and normal karyotypes and those with unknown significance were observed in five patients. In six patients, no karyotype was assessable. Classification in prognostic subgroups was performed as follows: favorable [inv(16), $t(8 ; 21), t(15 ; 17)]$, unfavorable $[-7,-5,5 \mathrm{q}-, 7 \mathrm{q}-$, inv(3), aberrations involving $11 \mathrm{q} 23$ and complex aberrations (three or more numerical or structural aberrations without involvement of prognostic favorable aberrations)], normal [46 (XY), 46 (XX)] and unknown significance [all others].

Determination of LC 50 and concentration coefficient in HL 60 and AML blasts

\section{HL 60 cells}

We determined the mean LC 50 of ErPC 3 in HL 60 cells after $24 \mathrm{~h}$ exposure to ErPC 3 as $7.0 \mu \mathrm{g} / \mathrm{ml}$ (median $6.6 \mu \mathrm{g} /$ $\mathrm{ml}$, range 4.0-11.0). The respective mean LC 50 after $72 \mathrm{~h}$ was $3.2 \mu \mathrm{g} / \mathrm{ml}$ (median $3.2 \mu \mathrm{g} / \mathrm{ml}$, range $2.1-4.3$ ). A typical example of one experiment is shown in Fig. 2. The mean LC 50 for cytarabine was $2.0 \mu \mathrm{g} / \mathrm{ml}$ after $24 \mathrm{~h}$ and $0.8 \mu \mathrm{g} / \mathrm{ml}$ after $72 \mathrm{~h}$. For idarubicine, values of LC 50 were 0.02 and $0.004 \mathrm{ng} / \mathrm{ml}$ and for etoposide 2.8 and $0.4 \mathrm{ng} / \mathrm{ml}$, respectively.

According to the equation given in the section "Patients and methods" the concentration coefficient $N$ was therefore calculated as a mean of 1.9 (median 1.4).

\section{Patient samples}

The median LC 50 of ErPC3 in freshly collected blasts from patients with AML was determined as $30.1 \mu \mathrm{g} / \mathrm{ml}$ (mean $29.2 \mu \mathrm{g} / \mathrm{ml}$, range 10.7-60.9) after $24 \mathrm{~h}$ exposition. The respective median LC 50 after $96 \mathrm{~h}$ was $8.6 \mu \mathrm{g} / \mathrm{ml}$ (mean $8.9 \mu \mathrm{g} / \mathrm{ml}$, range $0.6-16.7$ ). For cytarabine, the mean LC 50 was $20.7 \mu \mathrm{g} / \mathrm{ml}$ after $24 \mathrm{~h}$ and $0.6 \mu \mathrm{g} / \mathrm{ml}$ after $96 \mathrm{~h}$. For idarubicine, values of LC 50 were 1.7 and $0.9 \mathrm{ng} /$ $\mathrm{ml}$ and for etoposide 34.6 and $14.0 \mathrm{ng} / \mathrm{ml}$, respectively.

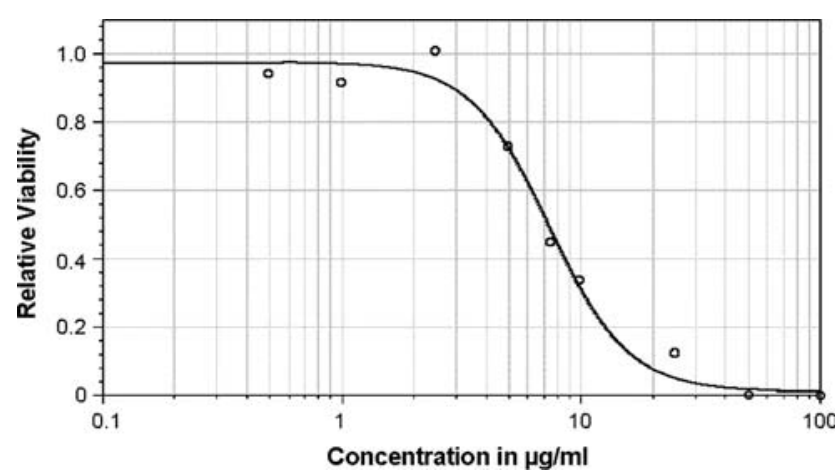

Fig. 2 Example of WST-1 assay in HL 60 cells after 24 h exposure to ErPC3. Dots represent the relative survival according to an untreated control at a certain concentration of ErPC3. From the resulting line, the LC 50 can be extracted 
The concentration coefficient $N$ for ErPC3 was calculated individually for each sample, and then the median value was calculated from these data. $N$ was therefore defined as 1.2 (mean 2.7, range 0.4-11.4)-implicating a similar relevance of both concentration $C$ and exposure time $T$ for the cytotoxic effect.

\section{Analysis of cytotoxicity of ErPC3 in HL 60 cells}

To characterize the mode of cell death inflicted by ErPC3, we used FACS analysis in HL 60 cells exposed to ErPC3. Only cells that stained positive for Annexin $\mathrm{V}$ and negative for 7-AAD were analyzed by 4-quadrant-statistics. This fraction represents cells in the early stage of apoptosis. The endogenous apoptotic fraction in HL 60 cells as shown by a positive staining for Annexin $\mathrm{V}$ [mean 21.4\% (median $20.0 \%$ )] was significantly raised by co-exposure to ErPC3. After $4 \mathrm{~h}$ exposure to ErPC3, the apoptotic fraction was significantly $(P<0.05)$ increased 4.5 -fold to a mean of $97.7 \%$ (median 97.6). Figure 3a (endogenous apoptosis) and Fig. 3b (apoptosis after 4-h exposure to ErPC3) show representative examples.

For further analysis of cell death, the number of cells with activated caspase 3 as one relevant inductor of classical apoptosis was measured. A mean of $10.9 \%$ (median $11.5 \%$ ) of HL 60 cells stained positive for endogenous activated forms of caspase 3 , and this fraction was significantly doubled $(P=0.02)$ by a 4 -h exposure to ErPC3 (mean 21.8\%, median 21.5\%). Figure 3c (endogenous activation of caspase 3 ) and Fig. 3d (after 4-h exposure with ErPC3) are showing histogram plots of FACS analysis of one representative experiment.

Analysis of synergy of ErPC3 with drugs in HL 60 cells and AML samples

\section{Cross-resistance}

For detection of cross-resistance, the logarithmic values of the respective LC 50s (ErPC3 and cytarabine, idarubicine and etoposide) obtained in each individual experiment were correlated (Pearson's test). We were unable to observe significant cross-resistance (represented by significant linear correlation) between ErPC3 and the established antileukemic agents in the AML samples after $96 \mathrm{~h}$ of incubation. The regression coefficient $r$ was -0.03 $(P=0.9)$ for cytarabine, $r=0.04(P=0.9)$ for idarubicine and $r=0.2(P=0.5)$ for etoposide.

\section{Interaction analysis in HL 60 cell line}

As it is unknown whether ErPC3 and cytarabine, etoposide and idarubicine are mutually exclusive or nonexclusive in
Fig. 3 Representative FACS analysis of apoptosis by ErPC3 in HL 60 cells. Upper line: Dot blots of Annexin V/7-AAD staining (a endogenous, $\mathbf{b}$ after exposure to ErPC3). Lower line: Histogram blots of active caspase 3 staining (c endogenous, $\mathbf{d}$ after exposure to ErPC3)
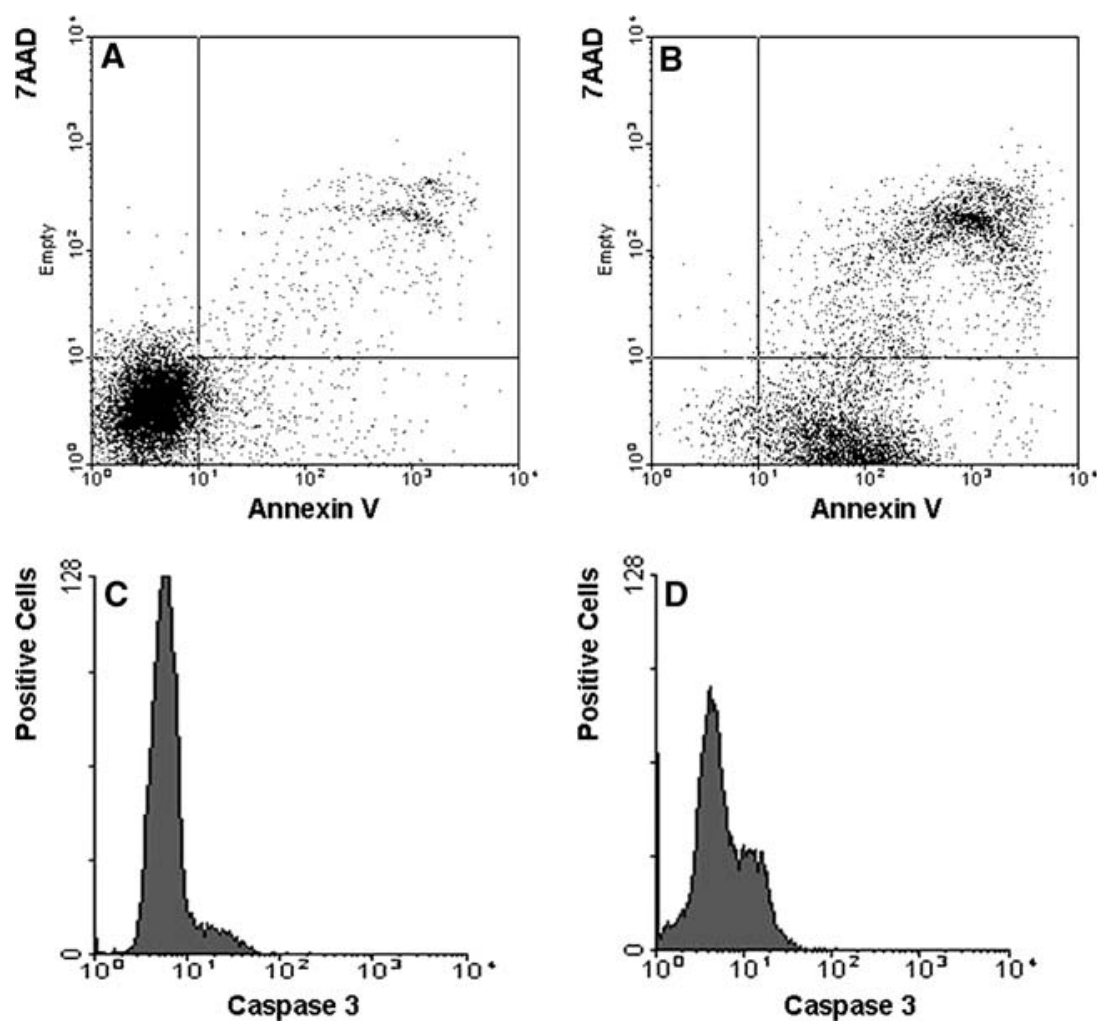
their mechanisms of action, we calculated the CI for both alternatives ( $\alpha=0$ and $\alpha=1)$. For calculation of the mean CI, it was calculated individually for each experiment and from the resulting CIs the mean was calculated. The results are given in Table 1. For cytarabine, additive interactions can be assumed with a minimum mean value of CI of 1.0 (for $\alpha=0$ after $24 \mathrm{~h}$ ) and a maximum mean value of 1.5 (for $\alpha=1$ after $72 \mathrm{~h}$ ). For etoposide mean values ranged between 1.2 (for $\alpha=0$ after $24 \mathrm{~h}$ ) and 1.8 (for $\alpha=1$ after $72 \mathrm{~h}$ ), indicating (sub-)additivity. However, the combination of idarubicine with ErPC3 resulted in much higher mean values with 1.6 (for $\alpha=0$ after $24 \mathrm{~h}$ ) and 5.6 (for $\alpha=1$ after $72 \mathrm{~h}$ ), respectively. These results imply antagonism for the combination of ErPC3 and idarubicine in HL60 cells.

For the construction of isobolograms, LC 50s and Modes I, IIa and IIb the mean results of all experiments were chosen (results after 72-h exposure were chosen for better accuracy). The data points (dots) for combinations of each experiment are shown individually in Fig. $4 \mathrm{a}-\mathrm{c}$ together with the mean value of all combinations (diamonds). The isobologram findings are consistent with the results of the respective combination index analysis. For cytarabine and etoposide (Fig. 4a, b) the individual outcomes (two supraadditive and one subadditive and antagonistic, respectively) accumulate in an additive mean which projects right into the envelope of additivity in both series. For idarubicine (Fig. 4c), two additive and one antagonistic sample add up to an antagonistic mean value which accordingly falls into the area of protection.

Table 1 Results of interactions analysis in HL 60 cells and patient samples

\begin{tabular}{lllll} 
HL 60 cell & & $\frac{\text { Patient samples }}{24 \mathrm{~h}}$ & $\frac{72 \mathrm{~h}}{24 \mathrm{~h}}$ \\
$\frac{\alpha=0 \quad \alpha=1}{\alpha=0 \quad \alpha=1}$ & $\frac{96 \mathrm{~h}}{\alpha=0 \quad \alpha=1}$ & $\alpha=0 \quad \alpha=1$ \\
\hline
\end{tabular}

ErPC3-cytarabine

\begin{tabular}{lllllllll} 
Mean & 1.0 & 1.3 & 1.1 & 1.5 & 1.0 & 1.2 & 1.6 & 2.1 \\
Median & 0.8 & 0.9 & 1.2 & 1.5 & 0.7 & 0.8 & 0.9 & 1.6 \\
ErPC3 - & \multicolumn{2}{c}{-toposide } \\
Mean & 1.2 & 1.4 & 1.3 & 1.8 & 1.2 & 1.4 & 1.2 & 1.4 \\
Median & 1.1 & 1.3 & 1.6 & 2.0 & 1.0 & 1.3 & 1.0 & 1.2 \\
ErPC3-idarubicine & & & & & & \\
Mean & 1.6 & 2.2 & 3.5 & 5.6 & 1.1 & 1.2 & 1.5 & 2.0 \\
Median & 1.5 & 2.1 & 2.1 & 3.0 & 1.1 & 2.3 & 1.4 & 1.6 \\
\hline
\end{tabular}

Values given are after $72-96 \mathrm{~h}$ exposure to the respective combination. Values $\sim 1$ are considered additive, $<1$ synergistic and values $>1$ antagonistic
Interaction analysis in patient samples

For calculation of the CI, each individual CI from the respective experiment was calculated and the median $\mathrm{CI}$ was assessed. The results of each combination of ErPC3 with cytarabine, etoposide and idarubicin are also given in Table 1. For the ErPC3-cytarabine combination, median values ranged between 0.7 (for $\alpha=0$ after $24 \mathrm{~h}$ ) and 1.6 (for $\alpha=1$ after $96 \mathrm{~h}$ ) and therefore predict an additive effect. The similar result can be assumed for the combination of ErPC3 and etoposide with median values of 1.0 (for $\alpha=0$ after $24 \mathrm{~h}$ ) and 1.3 (for $\alpha=1$ after $24 \mathrm{~h}$ ). The results for the ErPC3-idarubicine combination with median values of 1.1 (for $\alpha=0$ after $24 \mathrm{~h}$ ) and 2.3 (for $\alpha=1$ after $24 \mathrm{~h}$ ) predict a (sub-)additive outcome.

To construct an isobologram for analysis of the different patient samples, we chose the median values of the different LCs (LC 10-LC 50) obtained in the experiments after 96-h exposure to assess LC 50s, Mode I, IIa and IIb. The individual data points of combinations for each individual experiment were then drawn separately into the graph as dots with the median of all results depicted as diamond. The respective isobologram analysis are given in Fig. 4d-f. Figure 4d shows the result for ErPC3 and cytarabine. Most of the data points together with the median value project under the envelope of additivity and therefore indicate supraadditivity. For etoposide (Fig. 4e) the median value falls into the envelope of additivity, although coordinates of several data points projects also into the area of protection. Results of both analyses are in line with the results of combination indices. In contrast, for idarubicine and ErPC3, the result of the isobologram analysis implies mutual supraaddivity in patient samples, as the median value drops below the envelope of additivity (Fig. 4f) despite several data points projecting into the area of protection.

\section{Discussion}

The presented data show that ErPC3 exerts a high antileukemic activity in an AML cell line and also in freshly collected samples from patients with AML. LC 50s as a surrogate marker for the cell killing potential was $7.0 \mu \mathrm{g} /$ $\mathrm{ml}(13.9 \mu \mathrm{M})$ and $3.2 \mu \mathrm{g} / \mathrm{ml}(6.4 \mu \mathrm{M})$ after 24 and $72 \mathrm{~h}$ exposure in HL 60 cells and $30.1 \mu \mathrm{g} / \mathrm{ml}(59.8 \mu \mathrm{M})$ after $24 \mathrm{~h}$ and $8.6 \mu \mathrm{g} / \mathrm{ml}(17.1 \mu \mathrm{M})$ after $96 \mathrm{~h}$ in patient samples. From these data, the concentration coefficient $N$ for ErPC 3 can be determined as 1.9 for HL 60 cells and 1.2 for patient samples, therefore being close to 1 in both settings. Concluding from our experience of ex vivo drug measurement in AML [4, 6] exposure concentration as well as exposure time is (almost) equally important for this drug in 

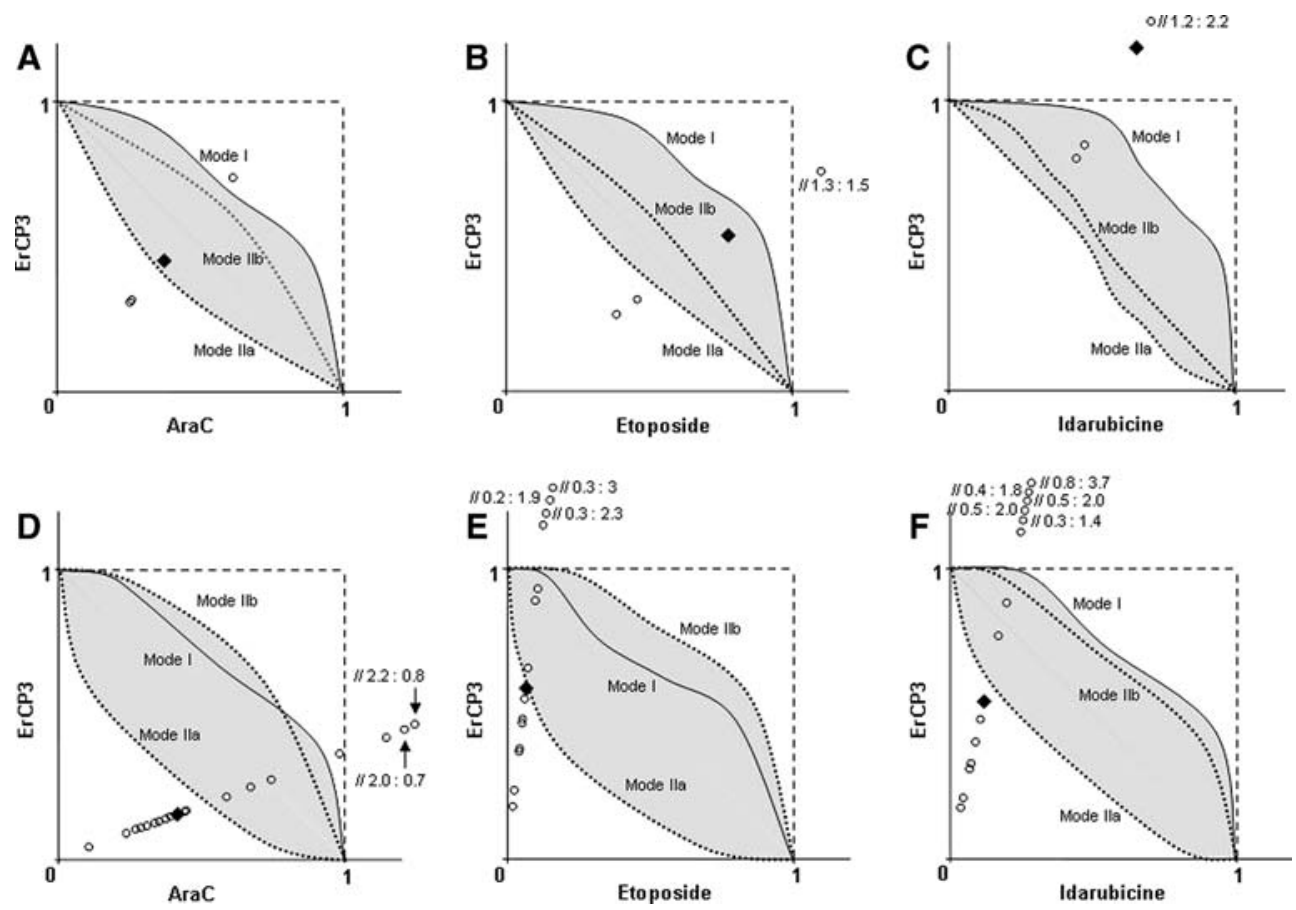

Fig. 4 Isobologram analysis of ErPC3 and AraC, etoposide and idarubicine interaction in HL 60 (upper line) and patient samples (lower line). The grey area surrounded by Mode I, IIa and IIb represents the "envelope of additivity". Dots represent individual

AML, especially in patient samples. Taking these data into account, the determined LC 50 for HL 60 cells in our study is higher than in previous studies that found the IC 50 for HL 60 cells to be $1.54 \mu \mathrm{M}$ [7]. The finding of an even higher LC 50 for ErPC3 in patient samples of $59.8 \mu \mathrm{M}$ stresses the relevance of in-vitro drug testing in fresh samples instead of model cell lines. A detailed pharmacokinetic analysis of ErPC3 is currently performed in the context of an ongoing phase I clinical study, preliminary data however show that plasma concentrations of more than $30 \mu \mathrm{g} / \mathrm{ml}$ ErPC 3 can be achieved in humans without toxicity (personal communication by L. Lindner). The in vitro analysis of ErPC3 performed in this study gives reasonable options how modulation of peak plasma concentrations can be achieved by adjustment of exposure time and administered concentration.

The observed decrease of tetrazolium metabolism by ErPC3 in the WST-1 assay can not be explained by growth inhibition alone and is therefore not termed IC 50 (inhibition of $50 \%$ cell growth). Rather, we were able to show that ErPC3 significantly increased the Annexin V positive fraction in HL 60 cells by 4.5 -fold. The cell death seems to be executed by apoptosis via activation of caspase 3 whose activity was doubled after exposure to ErPC3. This finding is in line with other experiments that showed classical apoptotic features of leukemic cell lines as DNA fragmentation, cell shrinkage and formation of apoptotic bodies experiments. Dots that fall outside the depicted area are marked with their coordinates. Diamonds represent mean value (in HL 60) and median value (in patient samples). For detailed description please refer to text

after exposure to alkylphosphocholines [5, 14]. Interestingly no cross resistance was seen in patient samples between ErPC3 and cytarabine, etoposide and idarubicine which implicate a functionally different mode of action of the alkylphosphocholines. To test their interaction in vitro, we performed simultaneous exposure of ErPC3 and AraC, etoposide and idarubicine in HL 60 cells and patient samples and analyzed the results by $\mathrm{CI}$ and isobologram analysis. The CI was calculated for both $\alpha=0$ and $\alpha=1$, however it seems unlikely that ErPC3 interferes with nucleoside metabolism or topoisomerase activity and could therefore considered mutually exclusive in their action. In HL60 cells the combination of ErPC3 with AraC and etoposide was additive by $\mathrm{CI}$ and isobologram analysis. For idarubicine, CI after $72 \mathrm{~h}$ suggested antagonism (especially for $\alpha=1$ ), as well as isobologram analysis. In patient samples these results were consistent except for idarubicine which was found to be (sub-)additive by CI and supraadditive by isobologram analysis. The reason for these different results remains unclear, however in respect of possible clinical applications, the outcome in fresh patients samples seems more relevant than those in AML models. With caution, it can therefore be concluded that these drugs augment each other in an additive way.

The question of "synergy" (i.e., supra-additivity) between ErPC3 and the other antileukemic agents may therefore be answered with "no"; however the definition 
of synergy as a larger effect of a combination of two (or more) drugs than the predicted effect of combined agents is far too simple. According to W. Greco, "the main rationale for combining anticancer agents (which are also effective individually) in the clinic is that by combining agents with non-overlapping toxic effects, more total tumor-killing poisons can be applied without increasing the overall toxicity to the host beyond acceptable limits" [8]. Especially in this context, alkylphosphocholines seem an attractive combination partner in the treatment of leukemias, as they are lacking myelosuppression as the major side effect of all other antileukemic agents. Rather, treatment with HePC results in an increase in leukocyte and thrombocyte count with a maximum effect of up to $20 \mathrm{G} / 1$ leucocytes and $700 \mathrm{G} / 1$ thrombocytes after 4 weeks $[21,22]$. This clinical finding was confirmed by the observation of co-stimulatory effects of HePC on granulopoesis [28] and thrombopoesis by increased synthesis and excretion of interleukin-6, thrombopoetin and granulocyte-macrophage colony-stimulating factor in vitro [3]. ErPC3 may feature similar effects but this has to be confirmed in man; however whether it stimulates myelopoiesis or just not compromises it remains almost alike, as in both cases the agent would render an ideal combination partner in highly myelotoxic polychemotherapy regimens applied to patients with an already insufficient hematopoiesis.

In conclusion, erufosine possess a high antileukemic activity in AML in vitro in both cell lines and patient samples by induction of apoptosis and acts additive to antileukemic drugs used in induction and consolidation therapy. This together with a (probable) attractive panel of side effects warrants further clinical studies of this drug in AML. The results of the ongoing phase I clinical trial of erufosine should be interesting with respect to future phase II studies with potential combinations partners for ErPC3 which have first been characterized in this study.

Acknowledgments Part of this work was performed in the context of the doctoral thesis of Matthias Juergens.

\section{References}

1. Berger MR, Sobottka SB, Konstantinov SM, Eibl H (1998) Erucylphosphocholine is the prototype of i.v. injectable alkylphosphocholines. Drugs Today 43:73-81

2. Berkovic D, Fleer EA, Breass J, et al (1997) The influence of 1beta-D-arabinofuranosylcytosine on the metabolism of phosphatidylcholine in human leukemic HL 60 and Raji cells. Leukemia 11:2079-2086

3. Berkovic D, Bensch M, Bertram J, et al (2001) Effects of hexadecylphosphocholine on thrombocytopoiesis. Eur $\mathrm{J}$ Cancer 37:503-511

4. Braess J, Fiegl M, Lorenz I, Waxenberger K, Hiddemann W (2005) Modeling the pharmacodynamics of highly schedule- dependent agents: exemplified by cytarabine-based regimens in acute myeloid leukemia. Clin Cancer Res 11:7415-7425

5. Engelmann J, Henke J, Willker W, et al (1996) Early stage monitoring of miltefosine induced apoptosis in KB cells by multinuclear NMR spectroscopy. Anticancer Res 16:1429-1439

6. Fiegl M, Juergens M, Hiddemann W, Braess J (2007) Cytotoxic activity of the third-generation bisphosphonate zoledronic acid in acute myeloid leukemia. Leuk Res 31:531-539

7. Georgieva MC, Konstantinov SM, Topashka-Ancheva M, Berger MR (2002) Combination effects of alkylphosphocholines and gemcitabine in malignant and normal hematopoietic cells. Cancer Lett 182:163-174

8. Greco WR, Faessel H, Levasseur L (1996) The search for cytotoxic synergy between anticancer agents: a case of Dorothy and the ruby slippers? J Natl Cancer Inst 88:699-700

9. Jendrossek V, Erdlenbruch B, Hunold A, et al (1999) Erucylphosphocholine, a novel antineoplastic ether lipid, blocks growth and induces apoptosis in brain tumor cell lines in vitro. Int J Oncol 14:15-22

10. Jha TK, Sundar S, Thakur CP, et al (1999) Miltefosine, an oral agent, for the treatment of Indian visceral leishmaniasis. N Engl J Med 341:1795-1800

11. Kano Y, Ohnuma T, Okano T, Holland JF (1988) Effects of vincristine in combination with methotrexate and other antitumor agents in human acute lymphoblastic leukemia cells in culture. Cancer Res 48:351-356

12. Kaufmann SH, Peereboom D, Buckwalter CA, et al (1996) Cytotoxic effects of topotecan combined with various anticancer agents in human cancer cell lines. J Natl Cancer Inst 88:734-741

13. Koehler KA, Hines J, Mansour EG, et al (1985) Comparison of the membrane-related effects of cytarabine and other agents on model membranes. Biochem Pharmacol 34:4025-4031

14. Konstantinov SM, Eibl H, Berger MR (1998) Alkylphosphocholines induce apoptosis in HL-60 and U-937 leukemic cells. Cancer Chemother Pharmacol 41:210-216

15. Konstantinov SM, Topashka-Ancheva M, Benner A, Berger MR (1998) Alkylphosphocholines: effects on human leukemic cell lines and normal bone marrow cells. Int J Cancer 77:778-786

16. Langen P, Maurer HR, Brachwitz H, et al (1992) Cytostatic effects of various alkyl phospholipid analogues on different cells in vitro. Anticancer Res 12:2109-2112

17. Leonard R, Hardy J, van Tienhoven G, et al (2001) Randomized, double-blind, placebo-controlled, multicenter trial of $6 \%$ miltefosine solution, a topical chemotherapy in cutaneous metastases from breast cancer. J Clin Oncol 19:4150-4159

18. Modolell M, Andreesen R, Pahlke W, Brugger U, Munder PG (1979) Disturbance of phospholipid metabolism during the selective destruction of tumor cells induced by alkyl-lysophospholipids. Cancer Res 39:4681-4686

19. Molecular Devices Corporation (1998) SOFTmax PRO-user manual, 2.4 edn. Molecular Devices Corporation, Sunnyvale

20. Mollinedo F, Fernandez-Luna JL, Gajate C, et al (1997) Selective induction of apoptosis in cancer cells by the ether lipid ET-18OCH3 (Edelfosine): molecular structure requirements, cellular uptake, and protection by $\mathrm{Bcl}-2$ and $\mathrm{Bcl}-\mathrm{X}(\mathrm{L})$. Cancer Res 57:1320-1328

21. Planting AS, Stoter G, Verweij J (1993) Phase II study of daily oral miltefosine (hexadecylphosphocholine) in advanced colorectal cancer. Eur J Cancer 29A:518-519

22. Pronk LC, Planting AS, Oosterom R, et al (1994) Increases in leucocyte and platelet counts induced by the alkyl phospholipid hexadecylphosphocholine. Eur J Cancer 30A:1019-1022

23. Ruiter GA, Zerp SF, Bartelink H, van Blitterswijk WJ, Verheij M (1999) Alkyl-lysophospholipids activate the SAPK/JNK pathway and enhance radiation-induced apoptosis. Cancer Res 59:24572463 
24. Ruiter GA, Zerp SF, Bartelink H, van Blitterswijk WJ, Verheij M (2003) Anti-cancer alkyl-lysophospholipids inhibit the phosphatidylinositol 3-kinase-Akt/PKB survival pathway. Anticancer Drugs 14:167-173

25. Sobottka SB, Berger MR, Eibl H (1993) Structure-activity relationships of four anti-cancer alkylphosphocholine derivatives in vitro and in vivo. Int J Cancer 53:418-425

26. Steel GG, Peckham MJ (1979) Exploitable mechanisms in combined radiotherapy-chemotherapy: the concept of additivity. Int J Radiat Oncol Biol Phys 5:85-91
27. Unger C, Fleer EA, Kotting J, Neumuller W, Eibl H (1992) Antitumoral activity of alkylphosphocholines and analogues in human leukemia cell lines. Prog Exp Tumor Res 34:25-32

28. Vehmeyer K, Kim DJ, Nagel GA, Eibl H, Unger C (1989) Effect of ether lipids on mouse granulocyte-macrophage progenitor cells. Cancer Chemother Pharmacol 24:58-60 